\title{
Trends in Cigarette Smoking in Kenya and the Challenges Impeding Cessation
}

\author{
Caren Kurgat $^{1}$, Joshua Kibet ${ }^{1,}$, , Bornes Mosonik ${ }^{1,2}$, Francis Opuru ${ }^{1}$ \\ ${ }^{1}$ Department of Chemistry, Egerton University, Njoro, Kenya \\ ${ }^{2}$ Department of Physical and Biological Sciences, Kabarak University, Nakuru, Kenya
}

Email address:

jkibet@egerton.ac.ke (J. Kibet)

${ }^{*}$ Corresponding author

\section{To cite this article:}

Caren Kurgat, Joshua Kibet, Bornes Mosonik, Francis Opuru. Trends in Cigarette Smoking in Kenya and the Challenges Impeding Cessation. American Journal of Biological and Environmental Statistics. Vol. 5, No. 1, 2019, pp. 7-15. doi: 10.11648/j.ajbes.20190501.12

Received: March 21, 2019; Accepted: May 7, 2019; Published: May 30, 2019

\begin{abstract}
Despite intense campaigns to minimize cigarette smoking owing to the socio-economic risks associated with it, cigarette smoking worldwide has continued to rise. This is a major concern to both public health authorities and medical practioners. This paper examines the Kenyan status on cigarette smoking through measurement of various parameters including mass media campaigns, taxation, level of education, nature of employment, and government legislation. Descriptive research design was employed because of its robust capability to give an in depth analysis of state of affairs as it exists in relation to cigarette smoking patterns in three Kenyan counties (Nakuru, Kisii and Migori). The study involved respondents above 18 years of age and was carried out between March and April 2018. Chi-square statistics was used to assess the association between various variables. It is clear from this study that most cigarette smokers had acquired high school education and above; representing $70 \%$ of the respondents. At $95 \%$ confidence limit, the p-value $=0.39$ and confidence interval, $C I=-1.965-4.156$. Therefore, cigarette smoking is dependent on the level of education. The odd ratio (OR) of 3.10 indicates a strong association between smoking and the level of education. This study also revealed that majority of the respondents smoked between 6 and 10 cigarettes per day (36\%). Besides, $50 \%$ of the target population admitted to being aware of the health hazards caused by cigarette smoking despite their continued smoking habits. This survey has demonstrated that most cigarette smokers are not only well educated but are aware of the dangers of cigarette smoking. Moreover, most respondents are addicted to cigarette smoking despite taxes imposed on tobacco products including cigarettes. This characteristic behaviour may be attributed to high unemployment rates in Kenya which this study has established as one of the major reasons for cigarette smoking.
\end{abstract}

Keywords: Cigarette Smoking, Public Health, Taxation, Mass Media Campaigns

\section{Introduction}

Statistics have shown that approximately 1.25 billion people worldwide use tobacco regularly out of which half of this population would eventually die from it [1]. Tobacco use is associated with 5 million deaths annually in the world and is regarded as one of the leading causes of premature deaths accounting for 1 in every 5 male deaths and 1 in 20 female deaths of those over the age of 30 [2]. Nearly $70 \%$ of cigarette smokers desire to quit cigarette smoking but few are successful, and even those who manage to quit, a good proportion require significant period of time before quitting altogether [3-4]. Recent data show that tobacco is responsible for the death of 1 in 10 adults globally with 2.41 million deaths occurring in developing countries and approximately 2.43 million deaths are reported in developed countries [5]. This study, nonetheless; will focus on tobacco cessation challenges in Kenya.

Accordingly, tobacco use in Kenya has been on the rise [6]. This situation has been aggravated by weak legislative policies, lack of funds to help sensitize the general public on the health impacts of cigarette smoking and poor mass media campaigns against cigarette smoking and tobacco abuse. Despite tobacco companies being compelled to label tobacco as a dangerous substance, there is little effort to ensure 
compliance [7]. Enforcement agencies tasked to campaign against cigarette smoking are reluctant to do so because tobacco companies are believed to be a source of significant income towards funding government programs in form of corporate tax [8]. The other very important factor that influences tobacco use is the poverty index occasioned mainly by youth unemployment [9]. Decisive measures to deter tobacco use in the country are largely lacking. Although the government has enacted some measures such as taxation of tobacco products through value added tax (VAT) and exercise duty, not much has changed on tobacco use. There is an urgent need by politicians to pass laws that would help minimize tobacco use and promote tobacco cessation.

The political class which is tasked with formulation and passing legislative policies to curb tobacco abuse has in one way or another been compromised by tobacco companies. Kenya is no exception. During the passing of Tobacco Control Act (TCA) in 2007, big tobacco companies sponsored the political class to shoot down the bill [5], and although, the bill was finally passed after a lot of pressure from the public and NGOs, it turned out to be a weak bill. Fundamentally, the role of the political class in tobacco control is well documented in literature [10-11]. Moreover, the mass media should come in to educate the population on the health impacts of cigarette smoking through digital platforms, print media and road shows. This is consistent with anti-tobacco mass media campaigns strategies applied in other countries towards achieving smoking cessation [11-13]. Smoking cessation is important for population health and comes with considerable health benefits both for individual smokers and public health authorities $[12,14]$. Demographic information on the use of tobacco in Kenya is alarming.

A rigorous study on substance abuse including tobacco abuse was conducted in 2014 in western Kenya and exposed shocking revelations on drug abuse in Kenya [15]. Statistics conducted earlier in 2008 on tobacco abuse indicated that central province was then leading at $30.4 \%$, Eastern $26 \%$, Coast 22.6\%, Nairobi 17.1\%, North Eastern 15.6\%, Rift valley $14.3 \%$, Western $11.2 \%$ and Nyanza $7.9 \%$ [16]. The survey revealed that male smokers in Kenya have a higher use of menthol and sweet menthol cigarettes (about 2 in 10 smokers of a usual brand), compared to male smokers in other international tobacco control (ITC) countries [17]. This is of critical concern for tobacco control efforts because flavourings such as menthol can activate cigarettes to deliver a smoother sensation in the respiratory system and the belief that these cigarettes are less harmful [17]. These figures are biased towards the male population since most females do not disclose their tobacco use status due to social cultural inhibitions and stigmatization [18]. Nonetheless, tobacco control in Kenya has realized significant gains in the recent past with the ratification of the WHO framework convention on tobacco control (FCTC) in 2004 and the passing of the Tobacco control act (TCA) in 2007 [19].

Significant steps have been made to insulate the noncigarette smoking population from the health problems caused by second hand smoking. As a result, the Kenyan government set up smoking zones for cigarette smokers although this does not assist cigarette smokers to quit cigarette smoking. Tobacco studies in Kenya are scarce in the literature primarily because of the reluctance by the state to invest in tobacco research despite the fact that cigarette smoking is one of the leading causes of cancer in the country. State agencies such as the Notational Authority for the Campaign against Drug Abuse (NACADA) mandated to check drug abuse including tobacco are underfunded; therefore their roles have been reduced only to administrative instead of conducting research and sensitizing the general public against the dangers of cigarette smoking. This study therefore takes a critical look at the major reasons for rampant abuse of tobacco products in Kenya, with special emphasis on cigarette smoking.

\section{Methodology and Research Design}

A cross section survey on the residents of Nakuru, Migori and Kisii counties was employed in this study. The sampling design involved purposive sampling where zones were randomly picked for questionnaires administration in the major towns and open air markets within the three counties. Moreover, data collection was done through key information interview and focused group discussion. Individual residents were targeted to provide information on the subject of study on voluntary basis. No inducements were provided to coerce or entice the respondents to fill the questionnaires. Survey tools were prepared in accordance with the parameters to be investigated. Accordingly, a set of 35 questions per questionnaire were drafted in English, translated to Swahili (Kenyan second official language), and issued to the respondents in the field. A field assistant interpreted the questions to the less educated in a language the respondents could understand. The questionnaires were structured to collect the data that helped the study to meet the research objectives. The study aimed at collecting information from respondents on their opinions regarding cigarette smoking. Descriptive survey research design was employed because of its in-depth investigative capabilities and the fact that it has a wide coverage as well as offering description of the state of affairs as it exists [20]. The primary data was cleaned and analysed using descriptive statistics, statistical package for social science (SPSS) version 25, Chi-square test and multivariate logistic regression.

\subsection{Sample Size Determination}

The study selected the entire sample of respondents using a stratified random sampling technique and the sample apportioned to the three counties equally. To determine the sample size, the standard formula developed by Kothari (2004) for a population $<10,000$ was used [20]. The proportion of the target population with desired smoking characteristic considering the fact that prior data was unknown was taken to be $10 \%$ at an allowed standard error of $5 \%$. A desired sample size of $n=138$ was therefore determined and applied in this study [20]. This study 
employed the questionnaire method in order to elicit responses on an array of question ranging from cigarette addiction, smoking behaviour, whether level of education and cost of cigarettes influenced their smoking patterns, and the economic benefits of cigarette smoking if any. Addiction to cigarette smoking (the habit to crave for a cigarette) was one of the most important parameters reported in this study. This habit is what triggers the urge towards tobacco abuse and is directly responsible for the cigarette smoking prevalence observed in this study.

\subsection{Study Area}

This study was conducted in three counties - Nakuru,
Migori and Kisii. Migori County for instance is well known for tobacco growing. These three Counties represent $20 \%$ of Kenya's total land mass and a representative, Kenyan population of approximately $10 \%$ according to 2009 census. The study was carried out between March and April 2018.

\section{Results and Discussion}

The study involved respondents above 18 years of age. The response rate was $72 \%$ out of which $44 \%$ were sampled in Nakuru County while $29 \%$ and $26 \%$ were sampled from Migori and Kisii counties respectively. The breakdown of the results is presented in Table 1 .

Table 1. Summary of the sociodemographic characteristics on cigarette smoking.

\begin{tabular}{|c|c|c|}
\hline Characteristics & Smoking Status & \\
\hline Age groups & Proportion (n) & $\%$ \\
\hline $18-25$ & 25 & 18 \\
\hline $26-35$ & 57 & 41 \\
\hline$>45$ & 30 & 15 \\
\hline \multicolumn{3}{|l|}{ Sex } \\
\hline Male & 109 & 79 \\
\hline \multicolumn{3}{|l|}{ Level of Education } \\
\hline Primary & 33 & 24 \\
\hline High school & 57 & 41 \\
\hline Tertiary & 40 & 29 \\
\hline No formal education & 8 & 6 \\
\hline \multicolumn{3}{|l|}{ Employment } \\
\hline Formal & 17 & 12 \\
\hline Informal & 109 & 79 \\
\hline \multicolumn{3}{|l|}{ Number of cigarette sticks smoked/day } \\
\hline $1-5$ & 43 & 31 \\
\hline $6-10$ & 50 & 36 \\
\hline $11-15$ & 12 & 9 \\
\hline$>15$ & 33 & 24 \\
\hline \multicolumn{3}{|l|}{ Effect of cigarette cost on cigarette smoking } \\
\hline Yes & 69 & 50 \\
\hline No & 65 & 47 \\
\hline May be Addiction to cigarette smoking & 3 & 3 \\
\hline Not at all & 29 & 21 \\
\hline Agree & 44 & 32 \\
\hline Strongly agree & 57 & 41 \\
\hline Not sure & 8 & 6 \\
\hline \multicolumn{3}{|l|}{ Cessation } \\
\hline Not ready & 33 & 24 \\
\hline \multicolumn{3}{|l|}{ Economic benefits of Tobacco } \\
\hline None & 52 & 38 \\
\hline Yes & 69 & 50 \\
\hline May be & 17 & 12 \\
\hline \multicolumn{3}{|l|}{ Strategies to minimize cigarette smoking } \\
\hline Campaign against smoking & 61 & 44 \\
\hline Tobacco control policies and legislation & 50 & 36 \\
\hline Personal choice to quit smoking & 18 & 13 \\
\hline Setting up rehabilitation centres & 9 & 7 \\
\hline
\end{tabular}

The entire sample consisted of both male and female respondents; $79 \%$ were male while $21 \%$ were female. In other countries, this margin is small despite men being heavy cigarette smokers [21]. Accordingly, this study explored the respondents from different sectors of employment. The study categorized employment under formal, informal and student (Figure 1a). The result was strikingly similar to the relationship between cigarette smoking and the level of 
education. This is true if we assume that most of the cigarette smokers with high school education and below work in the informal sector. This group constitute about $71 \%$ (Figure 1b). It is also valid to assume that not all cases who have University education work in the formal sector as some may be working in the informal sector.

(a)

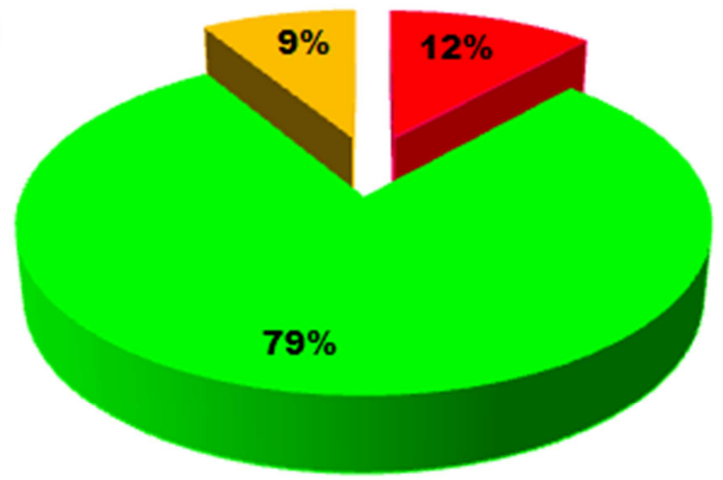

Formal Informal Student

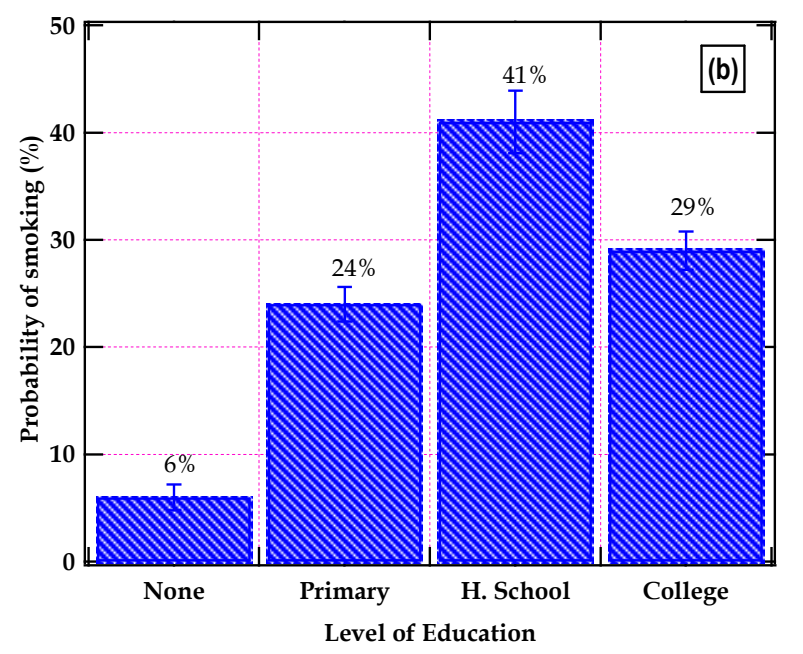

Figure 1. Nature of employment versus cigarette smoking (a) and (b) Level of education versus cigarette smoking.

The cross tabulation between the age bracket and smoking cigarette indicated that $38 \%$ of smokers were aged between 26 years and 35 years. This is an age width of 10 years and represents the age bracket with the most smokers. This represented the majority of the population addicted to tobacco use. From this study, it can be noted that the population above 45 years and those between 18-25 years of age formed the minority of the cigarette smoking community across the three counties. The age bracket of 26 and 45 constituted the bulk of the cigarette smokers - a combined total of $68 \%$, Figure $2 \mathrm{a}$. Besides, only $15 \%$ of the smokers were aged above 45 years which is the least number of smokers in the study area (Table 1, vide supra). The age distribution and the level of education as a function cigarette smoking are presented in Figure 2a.
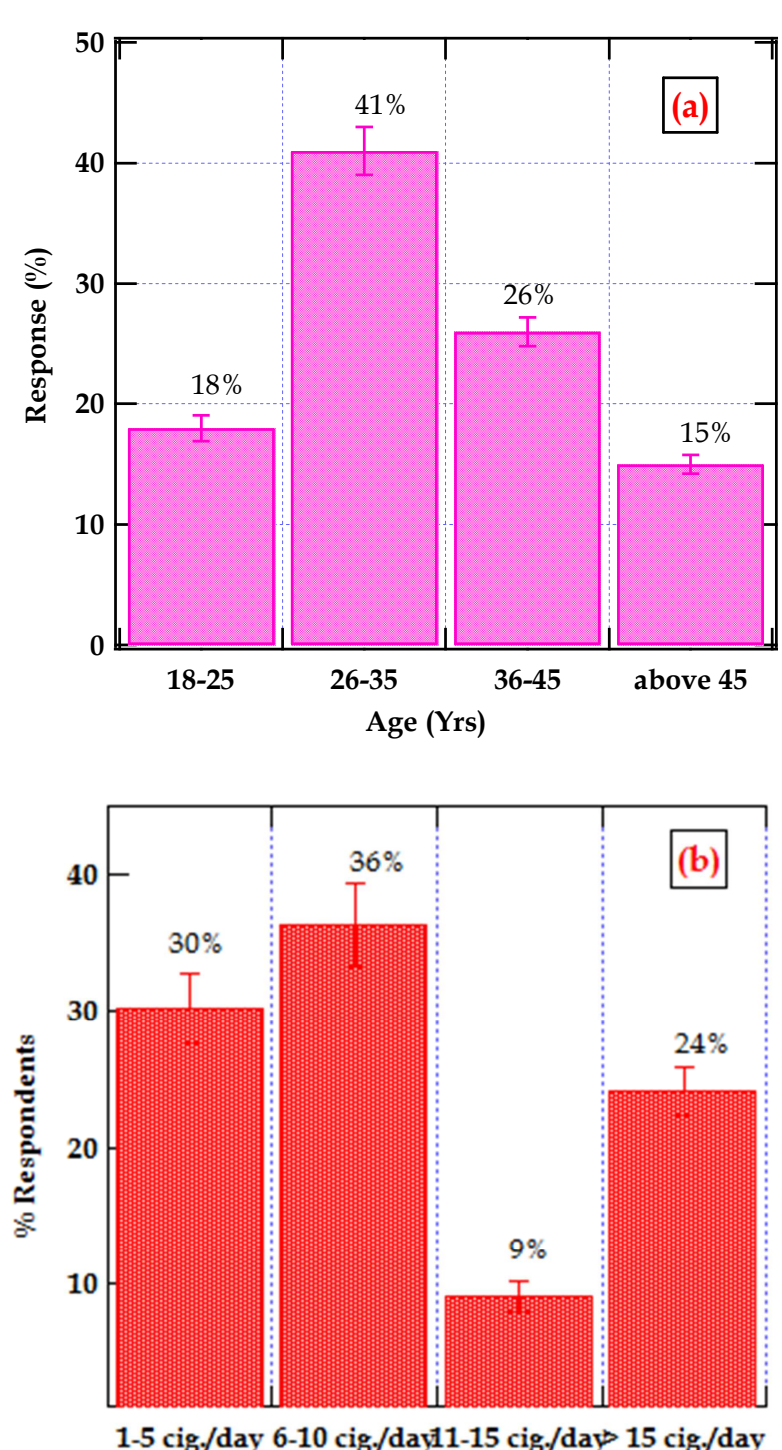

Figure 2. Distribution of cigarette smoking (a) age groups and (b) smoking intensity.

On the other hand, information on the smoking intensity is presented in Figure 2a. Clearly, 36\% of the sample population smoked between 6 and 10 cigarettes per day while $30 \%$ of the sampled population smoked between 1 and 5 cigarettes. Besides, $24 \%$ of the target population smoked more than 15 cigarettes per day while $9 \%$ smoked between 11 and 15 cigarettes per day. Evidently from this study, majority of cigarette smokers smoked between 6 and 10 cigarettes per day. The effect of education on cigarette smoking was also considered in this work. The respondents involved were the population with no formal education, primary education, high school education, and University education. The result of this investigation is captured in Table 1.

Chi-Square test and logistic regression analysis

Information on the smoking patterns, gender, employment, level of education attained were a mong the background characteristics that were compared using chi-square test and likelihood analysis (logistic regression). The outcome 
information obtained from the questionnaires is reported in this study. These scores were standardized and compared with a reference population that has a mean age of 36 and a standard deviation (SD) 10.

Table 2. Regression parameters from the respondents as a function of cigarette smoking.

\begin{tabular}{|c|c|c|c|c|c|c|c|c|}
\hline & Gender & $\begin{array}{l}\text { Addiction to cig. } \\
\text { smoking }\end{array}$ & $\begin{array}{l}\text { Level of } \\
\text { education }\end{array}$ & Employment & $\begin{array}{l}\text { Smoking } \\
\text { cessation }\end{array}$ & $\begin{array}{l}\text { Health impacts } \\
\text { of cig. smoking }\end{array}$ & Cost of cigarette & Smoking zones \\
\hline Coeff. & 1.30 & 1.06 & 0.98 & 0.43 & 1.09 & 0.72 & 0.92 & 1.60 \\
\hline $\begin{array}{l}\text { Odds ratio } \\
(\mathrm{OR})\end{array}$ & 2.15 & 4.32 & 3.10 & 3.04 & 5.20 & 2.00 & 2.50 & 5.00 \\
\hline Std. Err. & 4.84 & 7.18 & 5.07 & 4.73 & 7.03 & 4.30 & 5.912 & 7.64 \\
\hline $\mathrm{z}$ & 1.20 & 1.22 & 0.65 & 0.54 & 0.44 & 0.58 & 0.50 & 1.04 \\
\hline $\mathrm{P}>|\mathrm{z}|$ & 0.04 & 0.58 & 0.39 & 0.72 & 0.30 & 0.57 & 0.62 & 0.29 \\
\hline
\end{tabular}

Multivariate logistic regression (based on odds ratio analysis) was carried out to determine the health impact of cigarette smoking on the cigarette smoking population. Odds ratio (OR) analysis was used to indicate the extent of exposure in terms of smoking zones to the health outcome of cigarette smoking. All variables were analyzed using $p=0.09$ as limits for inclusion and $p=0.52$ for exclusion in the model (where $p$ stands for probability). The need to set up smoking zones for cigarette smokers was also tested. The final model was arrived at by manually adding or deleting variables while examining the changes in the coefficients. Consequently, $95 \%$ confidence level was chosen. The Number of observations from this study was 34 while the Log likelihood was calculated and found to be -6.95 . The result of this analysis is summarized in Table 2 .

The major tobacco component considered the driving force in tobacco addiction is nicotine [22]. Accordingly, if an individual stops smoking, the nicotine content in the brain will drop drastically thus causing the smoker to crave for a cigarette [23]. In order to change an addictive behaviour, an individual must go through a number of stages before finally quitting cigarette smoking altogether [24].

To determine whether cigarette smoking varies with various variables such as gender, employment, age, and level of education; a chi-square test was conducted. The $\mathrm{p}-$ value $=0.04$ was greater than $0.05 \%$ suggesting that smoking does not vary with gender and therefore it can be noted that smoking rate is similar among all sexes. From this study, the male population was found to be more prone to cigarette smoking as compared to their female counterparts. This is consistent with most African cultures and partly some western cultures which postulate that a woman who smokes a cigarette is a candidate for wayward behaviour and therefore cigarette smoking is unacceptable for women [25]. In most cases, this narrative has been found to be true [26]. Consequently, there seems to be a strong correlation between indecent behaviour among women and drug abuse in general. On the other hand, the cross tabulation between employment and cigarette smoking indicated that $79 \%$ of cigarette smokers were male while $15 \%$ were female.

Whereas the relationship between age groups and the intensity of cigarette smoking was not explored in the present study, it may be inferred that most of the respondents in the age bracket 26-35 probably smoked between 6-10 cigarette sticks per day. This assumption is based on the $\%$ level. For instance, those who indulge in cigarette smoking between the ages of 26-35 were the majority at $41 \%$ while those who smoked between 6-10 cigarettes per day stood at 36\%. The average time interval between cigarette smoking periods according to the information supplied by the respondents was determined to be $\sim 129$ minutes which translates to approximately two hours before one resumed smoking. The shortest time interval reported by some smokers was 10 minutes while the longest period was 360 minutes (the equivalent to 6 hours). This information is consistent with the cigarettes one smoked in a day. Evidently, the shorter the duration before craving for a cigarette, the more cigarette sticks one smoked per day.

The $\mathrm{p}-$ value $=0.72, C I=-1.208-3.345$, indicates that cigarette smoking varies with employment at 5\% confidence limit. If we consider the level of education as a function of cigarette smoking, the majority of the smokers had high school level of education. The p-value $=0.39$, $C I=-1.965-4.156$, was found to be greater than the significance level of 0.05 . Therefore, cigarette smoking is dependent on the level of education at $5 \%$ level of significance. On the other hand, the odds ratio (OR) was 3.10 implying a strong association of cigarette smoking with the level of education. Clearly, the majority of the respondents indulging in cigarette smoking were those who had acquired high school education. This figure stood at $41 \%$ of the total respondents. This result is remarkable. It implies one possible cause - most high school leavers were either unemployed or worked in the informal sector with little income. There must therefore be a correlation between unemployment, frustration, and cigarette smoking. Besides, the quality of cigarette smoked, though beyond the scope of this work is more likely to be the inexpensive type cigarettes. Coming in second among heavy smokers are those who had only acquired primary school education (24\%). Again, it can be inferred that this group are the less employed and probably the reason for their affinity towards smoking intentionally to deal with frustrating events. Nonetheless, it should be noted that most of the Kenyan population have acquired high school education. The literacy level in Kenya currently stands at approximately $78 \%$ [27]. Those who have acquired college education are more likely to be smoking for fun and in most cases to fit the old narrative that smoking is 'cool'. There is a probability that this category smoke high end cigarettes. In summary, the most educated group (those with high school education and above) constituted $70 \%$ of cigarette smokers 
monitored in this survey. This deduction is not statistically different from other studies elsewhere [28].

As to whether the cost of cigarette affected the intensity of cigarette smoking, $50 \%$ of the sample population believed that the cost of cigarettes affected their smoking pattern while $47 \%$ indicated that the cost of cigarettes did not affect their smoking behaviour. The minority $(3 \%)$ were not sure if the cost of cigarette smoking affected their smoking norms at all. This result was nearly split even among the respondents suggesting that the cost of a cigarette is a neutral parameter among the cigarette smoking community in the Kenya's three counties (Nakuru, Kisii and Migori). It has been argued clearly in literature that the heavy taxation of tobacco may help reduce tobacco use although tobacco industries have developed covert methods of making cigarettes cheaper [29]. The Kenyan experience is unique because the change in the price of cigarettes does not seem to deter cigarette smokers despite the lack of economic power to sustain the smoking characteristics.

Survey on the addiction characteristics of cigarette smokers showed that $41 \%$ of the sample strongly agreed that cigarette smoking was addictive whereas $32 \%$ of the sample population suggested they were not quite addicted. However, $21 \%$ of the respondents observed they were not addicted whereas the rest of the respondents $(6 \%)$ showed they were not sure if cigarette smoking was addictive. Addiction is one of the most important parameters measured in this survey with an odds ratio of 4.32 and $\mathrm{p}=0.58$ at a $C I=-1.209-$ 4.640 , suggesting that cigarette smoking is dependent on addiction at 0.05 significance level. These findings are remarkably interesting considering that approximately $73 \%$ of the total population surveyed are in one way or the other addicted to cigarette smoking. Chemically speaking, nicotine is the addictive ingredient in tobacco that causes cigarette smokers to desire smoking regularly and is usually triggered by a pleasurable feeling in the brain [30]. Nicotine dependence has two aspects; the persistence of smoking behaviour and the emergence of withdrawal symptoms upon cessation [31]. Current smokers, often addicted to nicotine, may need help and support to overcome their tobacco dependence [32]. Surveys suggest that three of four smokers wish to quit while a third attempt to quit every year but only $1-3 \%$ succeed in quitting the habit on their own [32]. In low middle income countries (LMICs), spontaneous quit rates are even lower [33]. This calls for concerted efforts in order to assist them to quit cigarette smoking.

The dangers of cigarette smoking on the health of the cigarette smoker were also explored. Accordingly, 50\% of the respondents noted that they were aware of the harmful effects of cigarette smoking on their health while $15 \%$ showed ignorance on the dangers of cigarette smoking. Nonetheless, $35 \%$ were not sure whether cigarette smoking precipitated negative health impacts. Additionally, these data is interesting and may point out to serious underlying causes as to why people choose to smoke. Evidently, the driving factors would be lack of proper sensitization on the grave effects of cigarette smoking, economic challenges which are serious precursors for frustration and 'don't care' attitude behaviour.

Smoking cessation refers to discontinuation of inhalation of tobacco products or the quitting of cigarette smoking for good [34]. Majority of the respondents in this survey were conversant with smoking cessation. The polled result showed that $73 \%$ of the sampled population indicated that they were aware of tobacco cessation while $24 \%$ were not aware. This is an important result because if such a large population is aware of smoking cessation, then why are they not quitting? There are many scenarios to examine why cessation is not working in the Kenyan context and probably other countries of similar experiences. A host of factors are to blame. Firstly, the poverty levels among the population which encourages smoking as an exit route to 'avoid' economic challenges. This is the 'meeting' point for socio-economic problems and tobacco initiated diseases such as cancer, cardiac arrest and cardiopulmonary diseases [35]. This survey noted that $41 \%$ of the respondents had the intention to quit smoking while $25 \%$ did not have any intention to quit. However, $34 \%$ were unable to declare whether to quit or not. This survey has noted that tobacco cessation in Kenya is far from being achieved because of dilution of policies by high political backing of Tobacco Industries, poverty levels, and lack of proper coordinated efforts by government agencies such as NACADA and the ministry of health $(\mathrm{MOH})$ to enforce tobacco control policies. Nonetheless, strategies aimed at controlling tobacco use should take into account heavy taxation on tobacco products despite proven behaviour by tobacco industry to undermine public health benefit realized from tobacco taxation through its pricing and covert advertisement strategies [29].

Although tobacco plant is harmful, it still has some economic benefits. Kenya collects approximately 5 billion shillings every year as tobacco revenue but on the contrary, the Kenya health sector uses 15 billion shillings to mop up tobacco related diseases in the country [36]. 50\% of the respondents indicated that tobacco is beneficial from an economic stand point - the government is getting tax revenues from tobacco companies and tobacco products while the farmers get some income from growing of tobacco which they eventually sell to Tobacco processing companies (TPC). Additionally, tobacco companies provide direct employment to some of the population and pay them well to work in TPC processing plants, research laboratories, and tobacco marketing. Tobacco farmers are supplied with tobacco seeds and fertilizers by TPC as inducements to continue growing tobacco. Therefore, these factors make it difficult to abandon tobacco farming which is a critical backbone for the survival of tobacco companies. More importantly, according to World Bank economic memorandum, the economic importance on tobacco in Kenya has more than tripled since 2005 [37]. This has earned tobacco farming a place as one of the most promising income generating activity in Kenya after tea, coffee, and horticultural products. Remarkably, tobacco as an economic activity has extensively penetrated developing countries 
because there has been a strong paradigm shift of tobacco companies from developed countries to developing countries lately - bringing with them the much needed revenues to poor countries [38]. This charm offensive appears to be working because one of the leading tobacco producers of tobacco leaf is Malawi [39]. The economic benefit of tobacco farming has been used by tobacco industries to veto tobacco control policies in most African countries including Kenya [38]. It is therefore incredible that most of the leading producers of tobacco, at least by 2012 were in the SubSaharan Africa (Malawi, Tanzania, Zambia, and Mozambique among other countries such as Kenya) [38-40].

Majority of the respondents strongly agreed that there was little sensitization on how to quit cigarette smoking and therefore suggested that the government authorities and mass media initiate public health policies towards the sensitization on the health hazards of cigarette smoking and general use of tobacco products. This would inform the general public on the options available towards quitting cigarette smoking for those already addicted to it. There is copious evidence that mass media campaigns backed by tobacco control programmes may promote quitting and reduce adult smoking [41]. The problem in the developing countries including Kenya is meeting the cost of such campaigns. This calls for the government and nongovernmental organizations to set aside funds for sensitizing the general public against the health hazards of tobacco products and promote cigarette smoking cessation.

Considering the negative health impacts of tobacco use, the respondents suggested ways in which these negative effects could be minimized. The most popular way proposed by $45 \%$ of the participants was sensitization on the health hazards caused by tobacco abuse. Besides, 36\% indicated that tobacco farming and tobacco processing should be regulated by the government while $13 \%$ believed that it was a personal initiative. The minority $(6 \%)$ indicated that setting up rehabilitation centres would promote smoking cessation.

Other factors advanced by the respondents that significantly contribute to cigarette smoking included curiosity and peer influence, smoking for pleasure, family background and upbringing, the type of job that an individual does, alcohol abuse, idleness due to lack of employment, lack of economic empowerment and frustrating events. Additionally, the subjects under study admitted that social media platform also plays a significant role towards recruiting people to indulge in cigarette smoking. Cigarette smoking in general, relates to heart disease, stroke, chronic obstructive pulmonary disease and several types of cancers some of which can be avoided by proper coordinated mechanisms towards controlling tobacco abuse [35].

Nonetheless, various loopholes have been systematically identified in the fight against cigarette smoking and the use of tobacco products in general; weak legislative practices, poor sensitization mechanisms against the dangers of cigarette smoking, strong correlation between poverty and cigarette smoking, and tobacco farming as an income earner. Moreover, cultural norms have been noted as a major disparity in smoking behaviour between men and women.
Kenyan culture and indeed that of most African countries put men at a higher pedestal when it comes to cigarette smoking thus male chauvinism designates men as the major victims of grave ailments caused by cigarette smoking.

This study has advanced one of the most in-depth analyses of the parameters that impede cigarette smoking cessation in Kenya and provides a missing link among cigarette smoking research inventories aimed at articulating why tobacco cessation may not be easy to achieve. The major drawback of this investigation is that a small representative fraction of the Kenyan population was sampled. Nevertheless, from the manner in which most participants responded to questionnaires there was a significant trend that similar data was likely to be collected if the entire country were to be sampled. We subscribe that this study is biased towards the cigarette smoking community in the three counties under study and does not discriminate between new cigarette smokers and previous cigarette smokers

\section{Conclusion}

These findings highlight the need for approaches that ensure that smokers get support to quit smoking across the country. It is also clear from this survey that despite knowledge on the health consequences associated with cigarette smoking, majority of the respondents continued to smoke. Those who suggested smoking zones to be set up were $\sim 5$ times more likely to be smokers as compared to those who believed smoking zones were not necessary. The individuals who reported that cigarette smoking has serious consequences on human health were more likely to be candidates of cigarette smoking. Furthermore, the survey showed that a significant number of the respondents were not deterred by the cost of the cigarette. Besides, the proposal to set up cigarette smoking zones as well possible harm and the cost of the cigarette was not likely to influence the smoking behaviour of an individual. Cigarette smoking in general may be traced to employment inequalities, poverty levels, and poor rehabilitation strategies. Although this study was conducted on a fraction of the Kenyan population, it was clear that similar results were likely to be replicated in other counties considering the manner in which the participants responded to certain questions in the questionnaire. From the findings reported in this work, a research based policy framework can be developed to assist in crafting measures towards tobacco cessation. Accordingly, the Kenyan experience, though peculiar in its aspect share similar smoking patterns with most countries around the world hence this study contributes significantly to the existing body of knowledge in tobacco research.

\section{Authors' Contributions}

JK designed the project while CK and BM prepared the questionnaires, and wrote the first draft of the manuscript. JK conducted quantitative calculations, interpreted the data and made critical suggestions towards the improvement of the 
manuscript. FO and JK critically reviewed the manuscript. All authors read and approved the final manuscript

\section{Conflict of Interests}

The authors declare that they have no competing interest

\section{Funding}

Egerton University grant \#EU/RE/DVC/072 is appreciated for funding this study

\section{Acknowledgements}

The authors wish to thank the National Commission for Science, Technology and Innovation (NACOSTI) for funding this study. The Directorate of Research and Extension (R\&E) of Egerton University is greatly appreciated for facilitating the administration of funds for this work.

\section{Consent for Publication}

Not applicable.

\section{References}

[1] J. Mackay, O. Shafey, M. Eriksen, H. Ross. The tobacco atlas. $3^{\text {rd }}$ Edition, American Cancer Society, Atlanta. (2009) (3) 38-9.

[2] D. K. Hatsukami, L. F Stead, P. C. Gupta. Tobacco addiction. The Lancet. (2008) (371) 2027-38.

[3] R. D. C. Rondina, R. Gorayeb, C. Botelho. Características psicológicas associadas ao comportamento de fumar tabaco. J. Bras. Pneumol. (2007) (33) 592-601.

[4] DuPont R and Gold M. Withdrawal and Reward: Implications for Detoxification and Relapse Prevention. Psychiatr. Ann. (1995) (25) 663-8.

[5] S. S. Shaik, D. Doshi, S. R Bandari, S. Kulkarn. Tobacco Use Cessation and Prevention - A Review. J Clin. Diagn. Res. 10 (5) (2016): Ze13-7.

[6] R. Brathwaite, J. Addo, L. Smeeth, K. Lock. A Systematic Review of Tobacco Smoking Prevalence and Description of Tobacco Control Strategies in Sub-Saharan African Countries; 2007 to 2014. PloS one, 10 (7) (2015). e0132401-e0132401.

[7] Consortium KTCSA. Situational analysis of tobacco control in Kenya: report of the baseline assessment carried out by the Kenya Tobacco Control Situational Analysis Consortium. 2008.

[8] P. Patel, J. Collin, A. B. Gilmore. "The law was actually drafted by us but the Government is to be congratulated on its wise actions": British American Tobacco and public policy in Kenya. Tob Control. 16 (1) (2007) 1-8.

[9] G. K. Gathecha. Tobacco control research in Kenya: the existing body of knowledge. Pan Afr Med J. 17 (2014) 155.

[10] F. T. Filippidis, C. Girvalaki, E. A. Mechili, C. I. Vardavas. Are political views related to smoking and support for tobacco control policies? A survey across 28 European countries. Tobacco Induced Diseases. 15 (45) (2017) 1-5.

[11] X. Zhang, T. D. Vuong, E. Andersen-Rodgers, A. Roeseler. Evaluation of California's 'Tobacco 21' law. Tob Control. (27) (2018) 656-662

[12] J. Dono, J. Bowden, S. Kim, C. Miller. Taking the pressure off the spring: the case of rebounding smoking rates when antitobacco campaigns ceased. Tob Control. (2018) 1-4.

[13] S. Gallus, M. S. Cattaruzza, G. Gorini, F. Faggiano. Vatican beats Italy $1-0$ in the tobacco endgame. Tobacco Control. (28) (2019) 239-240

[14] F. T. Filippidis, A. A. Laverty, U. Mons, C. Jimenez-Ruiz, C. I. Vardavas. Changes in smoking cessation assistance in the European Union between 2012 and 2017: pharmacotherapy versus counselling versus e-cigarettes. Tob Control. (2018) 16.

[15] L. Atwoli, P. A. Mungla, M. N. Ngung'u, K. C. Kinoti, E. M. Ogot. Prevalence of substance use among college students in Eldoret, western Kenya. BMC Psychiatry, 11 (1) (2011) 34.

[16] V. U. Ekpu, A. K. Brown. The economic impact of smoking and of reducing smoking prevalence: review of evidence. Tob use insights. (8) (2015) 1-35.

[17] D. L. Ashley, D. Burns, M. Djordjevic, E. Dybing, N. Gray, S. K. Hammond. The scientific basis of tobacco product regulation. World Health Organ Tech Rep Ser, (951) (2008) 1-277.

[18] L. Mpabulungi, A. S. Muula. Tobacco use among high shool students in Kampala, Uganda: questionnaire study. Croat. Med. J., 45(1) (2004) 80-83.

[19] P. Patel, J. Collin, A. B. Gilmore. "The law was actually drafted by us but the Government is to be congratulated on its wise actions": British American Tobacco and public policy in Kenya. Tob. Control. 16 (1) (2007) e1-e1.

[20] C. R. Kothari, Research Methodology: Methods and Techniques. $2^{\text {nd }}$ ed. 2004, New Delhi: New Age International Publishers, 1-414.

[21] S. A. E. Peters, R. R Huxley, M. Woodward. Do smoking habits differ between women and men in contemporary Western populations? Evidence from half a million people in the UK Biobank study. BMJ Open. 4 (12) (2014).

[22] T. F. Heatherton, L. Kozlowski. Nicotine addiction and its assessment. Ear. Nose Throat J. 69 (11) (1992) 763-767.

[23] R. West, S. Shiffman. Fast facts: smoking cessation. Karger Medical and Scientific Publishers (2016).

[24] Solomon, RL, Corbit JD. An opponent-process theory of motivation: II. Cigarette addiction. J Abnorm Psychol, 1973. 81 (2): $158-571$.

[25] A. K. Elkind. The social definition of women's smoking behaviour. Soc Sci Med. 20(12) (1985) 1269-78.

[26] B. T. Hansen, S. K. Kjær, C. Munk, L. Tryggvadottir, P. Sparén, M. Hagerup-Jenssen, K. L. Liaw, Nygård M. Early smoking initiation, sexual behavior and reproductive health a large population-based study of Nordic women. Prev. Med. (51 (1) (2010) 68-72.

[27] World Bank (2015). Adult Literacy. https://tcdata360.worldbank.org/indicators/f22e4196 
[28] S. E. Gilman, L. T. Martin, D. B. Abrams, I. Kawachi, L. Kubzansky, E. B. Loucks, R. Rende R, Rudd R, and Buka SL. Educational attainment and cigarette smoking: a causal association?. Int. J. Epidemiol. (37 (3) (2008) 615-24.

[29] R. Hiscock, J. Branston, A McNeill, S. C. Hitchman, T. R. Partos, A. B. Gilmore. Tobacco industry strategies undermine government tax policy: evidence from commercial data. Tob. Control. (27) (2018) 488-497.

[30] Dono J, Bowden J, Kim S, and Miller C. Taking the pressure off the spring: the case of rebounding smoking rates when antitobacco campaigns ceased. Tob. Control 28 (2) (2019) 233-236.

[31] Pergadia ML, Agrawal A, Heath AC, Martin NG, K. K. Bucholz, Madden, PAF. Nicotine withdrawal symptoms in adolescent and adult twins. Twin research and human genetics: The official journal of the International Society for Twin Studies. 13 (4) (2010). 359-369.

[32] M. Chaiton, L. Diemert, J. E. Cohen, S. J. Bondy, P. Selby, A. Philipneri, R. Schwartz. Estimating the number of quit attempts it takes to quit smoking successfully in a longitudinal cohort of smokers. BMJ, (6) (2016). e011045.

[33] S. Kamran, A. Lee. An integrated approach to treat tobacco addiction in countries with high tuberculosis incidence. Trop. Med. Int. Health. 14(4) (2009) 420-8.

[34] D. E Jorenby, S. J. Leischow, M. A. Nides, S. I. Rennard, J. A. Johnston, A. R. Hughes et al., A controlled trial of sustainedrelease bupropion, a nicotine patch, or both for smoking cessation. New Eng. J. Med. 340 (9) (1999) 685-691.
[35] A. D. M. Perez, I. M. Benseñor. Tobacco and alcohol use, sexual behavior and common mental disorders among military students at the Police Academy, São Paulo, Brazil. A crosssectional study. Sao Paulo Med J. (133) (2015) 235-44.

[36] K. J. Karimi, R. Ayah, T. Olewe. Adherence to the Tobacco Control Act, 2007: presence of a workplace policy on tobacco use in bars and restaurants in Nairobi, Kenya. BMJ. 6 (9) (2016) e012526-e012526.

[37] World Bank Group. Kenya country economic memorandum From economic growth and shared prosperity. World Bank, 2016. 103822: 1-164.

http://documents.worldbank.org/curated/en/763771468197384 854/pdf/103822-WP-Kenya-Country-EconomicMemorandum-PUBLIC.pdf

[38] T. W. Hu, A. H. Lee. Tobacco Control and Tobacco Farming in African Countries. J. Public Health Policy. 36 (1) (2015) 4151 .

[39] M. C. Kulik, S, A. Bialous, S. Munthali, W. Max. Tobacco growing and the sustainable development goals, Malawi. Bull. World Health Organ. 95 (5) (2017) 362-7.

[40] E. A. Lown, P. A McDaniel, R. E. Malone. Tobacco is "our industry and we must support it": Exploring the potential implications of Zimbabwe's accession to the Framework Convention on Tob. Control. Global Health. 12 (2) 2016 1-11.

[41] S. Durkin, E. Brennan, M. Wakefield. Mass media campaigns to promote smoking cessation among adults: an integrative review. Tob. Control. 21 (2) (2012) 127. 